\title{
Prevalence of behaviour disorders in low birthweight infants
}

\author{
P O D Pharoah, C J Stevenson, R W I Cooke, R C Stevenson
}

\begin{abstract}
Objective - To determine the prevalence of behaviour disorders in low birthweight infants.

Design - Children of birth weight $\leqslant 2000 \mathrm{~g}$ born to mothers resident in Merseyside in 1980-1 assessed using the Rutter parent and teacher behaviour questionnaires and the Conner modification of the Rutter teacher questionnaire. Children attending normal schools were assessed with controls matched for age, sex, and class in school. Children attending special schools were assessed unmatched.

Subjects - 233 matched case-control pairs attending normal primary schools and 46 unmatched children attending special schools.

Setting - Primary and special schools.

Main outcome measures - Emotional, conduct, and undifferentiated behaviour disorders and hyperactivity.

Results - On the parental questionnaire screen, $36 \%$ of the cases and $22 \%$ of the controls had a behaviour disorder and on the teacher questionnaire the proportions were $27 \%$ and $12 \%$ respectively. Hyperactivity was significantly more common among male cases than their controls $(21 \% v 5 \cdot 0 \%)$ but differed little among female cases and controls (9\% $v 7 \%)$.

Conclusions - Improving neonatal survival of low birthweight infants is accompanied by a higher prevalence of behaviour disorders. The long term implications for psychiatric morbidity and other adult disease must be monitored.

(Arch Dis Child 1994; 70: 271-274)
\end{abstract}

The present era of rapid evolution of neonatal intensive care has been associated with sharply declining mortality rates among low birthweight infants. ${ }^{1-4}$ Parallel with these advances, interest has focused on the quality of life of the survivors. For over a century it has been appreciated that clinically recognisable abnormalities such as cerebral palsy, epilepsy, and auditory and visual disabilities are more prevalent in low than in normal birthweight infants. This was explicit in the title of the paper with Little's original description of cerebral palsy. ${ }^{5}$ Subsequently, a wide variety of cognitive, motor, and behavioural abnormalities associated with prematurity were recognised, culminating in efforts to delineate specific syndromes such as 'organic behaviour syndromes', 6-12 'minimal cerebral dysfunction', ${ }^{13}$ and 'minimal brain dysfunction syndrome'. ${ }^{14}$
Coincident with the development of neonatal special and intensive care there has been a proliferation of studies that have attempted to monitor the outcome of this care. One recent review covered a total of 111 outcome studies that reported morbidity data in cohorts of infants of birth weight $<1500 \mathrm{~g}$ born since $1960 . .^{15}$ The majority of these studies have suffered because either no control population has been used for comparison or the cases studied were from a hospital based and not a geographically defined population. In the hospital based studies, there are likely to be biases attributable to differences in referral and admission policies. Furthermore, most outcome studies have been limited to an assessment of the prevalence of clinical disabilities or to measures of cognitive and motor performance. The prevalence of behaviour problems has received less attention. In this paper we report on differences in behaviour in a cohort of low birthweight infants from a geographically defined population and compared with matched controls.

\section{Methods}

We have previously reported on survival and morbidity in a cohort of infants when they were aged 3 years. This cohort was comprised of infants of birth weight $\leqslant 2000 \mathrm{~g}$, born in 1979 to 1981 to mothers whose area of residence at the time of the birth was in the five health districts which constitute the county of Merseyside. ${ }^{16}$ For the study being reported here, a subsample of this cohort was reassessed when aged 8-9 years to determine the prevalence of behaviour problems among them. The subsample is taken from those infants born in 1980 and 1981. The specific criteria used in selecting the subsample of cases and the controls, each individually matched with a case, have been previously described. ${ }^{17}$ Controls were selected for only those index children attending a normal mainstream school. Index children attending special schools are considered separately as an unmatched group.

\section{ASSESSMENT OF BEHAVIOUR}

The behaviour of the children was assessed using Rutter screening questionnaires completed by parents and teachers. The Rutter behaviour scale for parents consists of 32 statements concerning the child's behaviour. The frequency of the occurrence of the behaviour, or the degree of its severity, or the extent to which the statement applies to the child is scored 0,1 , or 2 producing a total score within the range 0 to $64 .^{18} 19$
Correspondence to: Professor P O D Pharoah, Department of Public Health, PO Box 147

Accepted 22 October 1993 
The completion of the parent questionnaire was carried out either when the child was being assessed at the school or, if a parent was not present on that occasion, the questionnaire was posted to the child's home.

The teacher component of the Rutter behaviour scale consists of 26 brief statements each of which is scored 0,1 , or 2 producing a total score within the range 0 to $52 .{ }^{20}$

According to set rules concerning the score obtained by the child, categorisation can be made as to whether a conduct (aggressive, disobedient, antisocial), emotional (anxious, miserable, phobic, somatic), or undifferentiated disorder is present.

For the majority, the teacher questionnaire was completed at the time the child was assessed at school. Occasionally the teacher returned the completed questionnaire by post.

In some instances, not all the 32 items on the parent questionnaire or the 26 items on the teacher questionnaire were completed. Analyses were carried out if at least 30 items on the parent and 24 items on the teacher questionnaire had been completed.

\section{HYPERACTIVITY}

Three items (restless, fidgety, not settling to activities) each on the teacher and the parent Rutter questionnaires, which are not part of the emotional or conduct disorder subscales, enable the child to be categorised as hyperactive. A score of at least $3 / 6$ on both questionnaires is required to be placed in this category.

In addition, the Conners' modification, which used the Rutter teacher questionnaire only, takes the mean score of eight specific questions and, if over 1.5 , hyperactivity is indicated. ${ }^{21}$

\section{Results}

The study sample consists of 304 children (220 of birth weight $\leqslant 1500 \mathrm{~g}$ and 84 of birth weight $1501-2000 \mathrm{~g}$ ) one of whom died as the result of a non-accidental injury. The flow chart depicting the selection of the study sample and the proportions successfully followed up and assessed are reported in the accompanying paper. ${ }^{17}$ An important feature of the study was the $92 \%$ follow up rate achieved.

\section{EFFECTIVENESS OF MATCHING}

No significant differences were found, between cases and controls, for the proportion of families with only one child, the social class

Table 1 Case-control comparison of type of disorder; figures are number (\%)

\begin{tabular}{llllll}
\hline \multirow{2}{*}{$\begin{array}{l}\text { Type of behaviour } \\
\text { disorder }\end{array}$} & \multicolumn{2}{l}{ Parent questionnaire } & & \multicolumn{2}{l}{ Teacher questionnaire } \\
\cline { 2 - 3 } \cline { 5 - 6 } \cline { 5 - 6 } & Cases & Controls & & Cases & Controls \\
\hline None & $141(61)$ & $175(75)$ & & $169(73)$ & $205(88)$ \\
Emotional & $40(17)$ & $30(13)$ & & $35(15)$ & $7(3)$ \\
Conduct & $29(12)$ & $11(5)$ & & $22(9)$ & $16(7)$ \\
Undifferentiated & $15(6)$ & $11(5)$ & & $7(3)$ & $5(2)$ \\
Missing data & $8(3)$ & $6(3)$ & & 0 & 0 \\
Total & $233(100)$ & $233(100)$ & & $233(100)$ & $233(100)$ \\
\hline
\end{tabular}

and employment status of the father, the income of the mother or the father, parental attendance at further education and the type of housing, that is whether owner occupied, local authority, or housing association dwelling. However, although none of these differences were statistically significant, the differences that were found tended to be more favourable for the controls.

The detailed comparison of these variables is reported in the accompanying paper. ${ }^{17}$

\section{BEHAVIOUR ASSESSMENT}

Children attending normal schools (cases and controls)

Comparison of the case-control pairs showed that $36 \%$ of cases and $22 \%$ of controls had a behaviour disorder on the parental questionnaire. On the teacher questionnaire the proportions were $27 \%$ and $12 \%$ respectively. These differences between cases and controls are highly statistically significant $(p<0.001)$. The prevalence and classification by the type of behaviour disorder is shown in table 1 ; on this screening, both emotional and conduct disorders are more common among cases than controls.

In both the cases and controls, the parent questionnaire was more likely than the teacher questionnaire to indicate that a behavioural disorder was present. The concordance between the parent and teacher as to whether or not a behavioural disorder was present was $60.4 \%$ for the cases and $74.4 \%$ for the controls.

Children with a pervasive disorder are those who have a high score on both questionnaires. This was present in $13 \%$ of cases and $4 \%$ of controls. These data are shown in table 2 .

\section{Hyperactivity}

There was a highly statistically significant difference in the proportion of hyperactive children among cases compared with controls on the Rutter assessment scale $(14.7 \% v$ $6.0 \%)$. On the Conners' scale the case-control difference did not attain statistical significance $(12.0 \% v 7.0 \%)$. Sex specific analysis of the data showed that, for both cases and controls, hyperactivity was more prevalent among boys than girls.

A striking feature, however, was that a significant difference between cases and controls was found only among boys for both the Rutter $\left(\chi^{2}, 2 \mathrm{df}=10.3 ; \mathrm{p}<0.01\right)$ and the

Table 2 Concordance between parents and teachers on assessment of behavioural disorder; figures are number (\%)

\begin{tabular}{|c|c|c|c|}
\hline \multirow{2}{*}{\multicolumn{2}{|c|}{ Teacher questionnaire }} & \multicolumn{2}{|c|}{ Parent questionnaire } \\
\hline & & $\begin{array}{l}\text { Disorder } \\
\text { present }\end{array}$ & $\begin{array}{l}\text { Disorder } \\
\text { absent }\end{array}$ \\
\hline \multicolumn{4}{|c|}{ Cases $(n=225)$} \\
\hline Disorder & $\begin{array}{l}\text { Present } \\
\text { Absent }\end{array}$ & $\begin{array}{l}29(13) \\
55(24)\end{array}$ & $\begin{array}{r}34(14) \\
107(48)\end{array}$ \\
\hline \multicolumn{4}{|c|}{ Controls $(n=227)$} \\
\hline Disorder & $\begin{array}{l}\text { Present } \\
\text { Absent }\end{array}$ & $\begin{array}{l}10(4) \\
42(19)\end{array}$ & $\begin{array}{c}16(7) \\
159(70)\end{array}$ \\
\hline
\end{tabular}


Table 3 Prevalence of hyperactivity; figures are number (\%)

\begin{tabular}{lcc}
\hline & Cases & Controls \\
\hline Rutter assessment & $197(85)$ & $218(94)$ \\
Not hyperactive & $34(15)$ & $14(6)$ \\
Hyperactive & $2(1)$ & $1(0)$ \\
Missing data & $198(85)$ & $213(91)$ \\
Conners'assessment & $27(12)$ & $16(7)$ \\
Not hyperactive & $8(3)$ & $4(2)$ \\
Hyperactive & $233(100)$ & $233(100)$ \\
Missing data & & \\
Total & & \\
\hline
\end{tabular}

Conners' $\left(\chi^{2}, 2 \mathrm{df}=4.9 ; \mathrm{p}<0 \cdot 05\right)$ assessments. The prevalence of hyperactivity among girls was similar for cases and controls in both assessments (table 3).

\section{Children attending special schools (unmatched cases)}

There were 46 children attending special schools. In 40 of these, the parent questionnaires had complete data and $29(73 \%)$ of the children were screened as having a behaviour disorder. The teacher questionnaire was completed for 43 of the 46 children and 18 $(42 \%)$ had a behaviour disorder. The classification by type of disorder according to parent and teacher questionnaires is shown in table 4. On this screening, each type of behaviour disorder was more prevalent according to the parent compared with the teacher questionnaire.

\section{Hyperactivity and learning disability}

There is a striking association between the prevalence of hyperactivity and the level of learning disability as determined by the Wechsler intelligence scale for children. When

Table 4 Children attending special school (unmatched cases): prevalence of behavioural disorder on screening; figures are number (\%)

\begin{tabular}{lll}
\hline Type of disorder & $\begin{array}{l}\text { Parent } \\
\text { questionnaire }\end{array}$ & $\begin{array}{l}\text { Teacher } \\
\text { questionnaire }\end{array}$ \\
\hline None & $11(24)$ & $25(54)$ \\
Emotional & $16(35)$ & $9(20)$ \\
Conduct & $9(20)$ & $7(15)$ \\
Undifferentiated & $4(9)$ & $2(4)$ \\
Missing data & $6(13)$ & $3(7)$ \\
Total & $46(100)$ & $46(100)$ \\
\hline
\end{tabular}

Table 5 Hyperactivity in relation to learning disability; figures are number (\%)

\begin{tabular}{llr}
\hline & \multicolumn{2}{l}{ Hyperactivity } \\
\cline { 2 - 3 } & Present & Absent \\
\hline IQ $<70$ & $5(71)$ & $2(29)$ \\
$\quad$ Cases & $2(100)$ & 0 \\
$\quad$ Controls & $9(31)$ & $20(69)$ \\
All & $16(42)$ & $22(58)$ \\
IQ 70-85 & $7(15)$ & $39(85)$ \\
$\quad$ Cases & $2(18)$ & $9(82)$ \\
Controls $\quad 2(20)$ & $8(80)$ \\
All & $11(16)$ & $56(84)$ \\
IQ $>85$ & & \\
$\quad$ Cases & $22(12)$ & $156(88)$ \\
Controls & $10(5)$ & $208(95)$ \\
Children at special school & $1(25)$ & $3(75)$ \\
All & $33(8)$ & $367(92)$ \\
\hline
\end{tabular}

all three groups of children, that is cases, controls, and those attending special schools, were combined the prevalence of hyperactivity was $42 \%, 16 \%$, and $11 \%$ in three arbitrarily defined IQ groups, $<70,70-85$, and $>85$ respectively. This trend is highly statistically significant ( $\chi^{2}$ for trend, $1 \mathrm{df}=6.0 ; \mathrm{p}<0.0001$; table 5).

\section{Discussion}

The Rutter parent and teacher scales are screening instruments that have been extensively used to assess the prevalence of psychiatric disorder in children. They have acceptable inter-rater and retest reliabilities. ${ }^{1820}$ The validity of any screening test is determined by its sensitivity, that is its ability to correctly diagnose those with the disease and the specificity, that is the ability to correctly diagnose those without the disease. The cut off point of the Rutter questionnaire score has been validated using, as criterion standards, children attending psychiatric clinics and children having intensive psychiatric interviews. ${ }^{182022}$ Problems arise in the interpretation of the rating scales in children with major impairments and the data provided here of the behaviour rating of those children attending special schools must be interpreted with caution. However, the results of this study show that the index low birthweight children attending normal schools have a significantly higher prevalence of behaviour disorder when aged 10 years than their matched controls. Moreover, as the cases and controls were matched by school, the difference must be primarily attributable to factors outside the school environment or to an interaction between the school environment and factors outside the school.

The long term relevance of these observations is less predictable. What will be the subsequent behaviour disorders and psychiatric problems associated with deviant scores in the children when they were aged 10 years? In a follow up of the children in the National Child Development Study, ${ }^{23}$ there were only moderate correlations between the behaviour ratings at ages 7,11 , and 16 years. The majority of children in the 'deviant' (top 13\%) group at one age had moved out of that group by a later follow up. ${ }^{24}$ The possible long term psychiatric morbidity associated with being of low birth weight requires an extended longitudinal follow up of these children.

Studies of hyperactivity have been hampered by difficulties in the definition of the syndrome. ${ }^{25} 26$ The distinction can be drawn between 'pervasive' hyperactivity which is found in a variety of different settings, 'school' hyperactivity which is found at school and not at home, and 'home' hyperactivity which is found at home and not at school. ${ }^{27}$ It is well known that hyperactivity is more common among boys than girls and is found even when the gender comparison is confined to mixed sex twin pairs, thereby matching perfectly for several biological and social variables. ${ }^{28}$ In the low birthweight cohort reported here, this 
gender difference is again confirmed. However, the difference between cases and controls is found only for boys and not girls. This may be a chance observation and will need to be confirmed in other studies. If it is confirmed, then, for girls, the factors leading to low birth weight cannot be contributors to the hyperactivity. The case control difference in boys must be due to a factor(s) not associated with low birth weight or to an interaction effect of these factor(s) with low birth weight. Alternatively, a low birthweight effect may be solely responsible for the difference in boys but this would mean that there are gender differences in the factors leading to low birth weight which is inherently unlikely.

This study adds to the wide range of morbidity that is found to be more prevalent among low birthweight infants than their normal birthweight peers, even when they are matched on several important variables. The improved survival of these infants has implications for health, education, and social services. The long term effects are largely an unknown quantity: the index children reported here who attended normal school were clinically unremarkable but showed a difference from the controls with more in-depth assessments. Currently there is considerable interest in, and a great deal of evidence for, the hypothesis that several diseases of major public health importance have their origins in fetal and infant life. ${ }^{29}$ Low birth weight and its corollaries of prematurity and growth retardation are indicators that fetal development is suboptimal. It is imperative that the long term effects are monitored, either by the extended follow up of a series of cohorts of infants, which is expensive, or by establishing a well maintained routine data system.

The authors are most grateful to the Department of Health who funded the study, Hilary Goodman and Rita Angelica who assisted in the collection of the data, and Chris West and Paul assisted in the collection of the data, and Chris West

1 Alberman E, Botting B. Trends in prevalence and survival of very low birthweight infants, England and Wales: 1983-7. Arch Dis Child 1991; 66: 1304-8.

2 Pharoah POD, Alberman ED. Mortality of low birthweight infants in England and Wales 1953-1979. Arch Dis Child 1985; 56: 86-9.

3 Hack M, Merkatz IR, Jones PK, Fanaroff AA. Changing trends of neonatal and postneonatal deaths in very-low797-800.
4 Cooke RWI. Trends in preterm survival and incidence of cerebral haemorrhage 1980-89. Arch Dis Child 1991; 66: 403-7.

5 Little WJ. On the incidence of abnormal parturition, difficult labour, premature birth and asphyxia neonatorum on the mental and physical condition of the child especially in relation to deformities. Transactions of the Obstetric Society of London 1862; 3: 293-344.

6 Kann E, Cohen LH. Organic driveness: a brainstem syndrome and an experience. N Engl f Med 1934; 210: 748-56.

7 Bradley C. Characteristics and management of children with behaviour problems associated with organic brain damage. Pediatr Clin North Am 1957; 4: 1049-60.

8 Strauss AA, Lehtinen LE. Psychopathology and education of the brain-injured child. New York: Grune and Stratton, 1947.

9 Strauss AA, Kephart NC. Psychopathology and education of the brain-injured child. New York: Grune and Stratton, 1955

10 Rosenfeld GB, Bradley C. Childhood behavior sequelae of asphyxia in infancy with special reference to pertussis and asphyxia neonatorum. Pediatrics 1948; 2: 74-84.

11 Bender L. Psychopathology of children with organic brain disorders. Springfield, Illinois: CC Thomas, 1956.

12 Eisenberg L. Psychiatric implications of brain damage in children. Psychiatr $Q$ 1957; 31: 72-92.

13 MacKeith R. Defining the concept of 'minimal brain damage'. In: MacKeith R, Bax M, eds. Minimal cerebral dysfunction. (Clinics in developmental medicine No 10.) London: Heinemann, 1963: 1-9.

14 Clements SD. Minimal brain dysfunction in children NINDB monograph No 3.) Washington DC: US (NINDB monograph No 3.) Washington DC:

15 Escobar GJ, Littenberg B, Pettiti DB. Outcome among surviving very low birthweight infants: a meta-analysis. Arch Dis Child 1991; 66: 204-12.

16 Powell TG, Pharoah POD, Cooke RWI. Survival and morbidity in a geographically defined population of low birthweight infants. Lancet 1986; i: 539-43.

17 Pharoah POD, Stevenson CJ, Cooke RWI, Stevenson RC. Clinical and subclinical deficits at 8 years in a geographically defined cohort of low birthweight infants. Arch Dis Child 1994; 70: 264-70.

18 Rutter M, Tizard J, Whitmore K, eds. Education, health and behaviour. London: Longman, 1970.

19 Rutter M, Tizard J, Yule W, Graham P, Whitmore K. Research report: Isle of Wight studies, 1964-1974. Psychol Med 1976; 6: 313-32.

20 Rutter M. A children's behaviour questionnaire for completion by teachers: preliminary findings. $\mathcal{f}$ Child Psychol Psychiatry 1967; 8: 1-11.

21 Conners CK. A teacher rating scale for use in drug studies with children. Am $\mathcal{F}$ Psychiatry 1969; 126: 884-8.

22 Rutter $R$, Cox A Tupling $C$, Berger $M$, Yule W. Attainment and adjustment in two geographical areas. I: The prevalence of p

23 Davie R, Butler N, Goldstein H. From birth to seven. Davie R, Butler N, Goldst
London: Longman, 1972.

24 Ghodsian $M$, Fogelman $\mathrm{K}$, Lambert L, Tibbenham A. Changes in behaviour ratings of a national sample of children. British fournal of Social and Clinical Psychology 1980; 19: 247-56.

25 Taylor EA. Cultural differences in hyperactivity. Advances in Developmental and Behavioural Pediatrics 1987; 8: 125-50.

26 Taylor E, Sandberg S, Thorley G, Giles S. The epidemiology of childhood hyperactivity. (Institute of Psychiatry of childhood hyperactivity. No 33.) Oxford: Oxford Maudsley Monograph

27 Schachar R, Rutter M, Smith A. The characteristics of situationally and pervasively hyperactive children: implications for syndrome definition. F Child Psychol Psychiatry 1981; 4: 375-92.

28 Goodman R, Stevenson J. A twin study of hyperactivity - I An examination of hyperactivity scores and categories derived from Rutter teacher and parent questionnaires. f Child Psychol Psychiatry 1989; 30: 671-89.

29 Barker DJP, ed. Fetal and infant origins of adult disease. London: BMJ Publishing Group, 1992. 